\title{
Three years' experience of sexually transmitted diseases in Seville, Spain*
}

\author{
E J PEREA, C ALVAREZ-DARDET, M V BOROBIO, J M BEDOYA JUN, \\ J ESCUDERO, R M GALLARDO, B GONZÁLEZ-GABALDÓN, C DE MIGUEL, \\ J C MORENO, A PÉREZ-BERNAL, AND A RODRIGUEZ-PICHARDO \\ From the STD Diagnostic Centre and the Department of Microbiology, University of Seville Medical \\ School, Seville, Spain
}

SUMMARY At present there are no reliable statistics on the relative prevalences of sexually transmitted diseases (STDs) in Spain. In a report of the first three years' experience in an STD diagnostic centre between 1977 and 1979 a total of 879 patients (534 men and 345 women) were seen. They mainly consisted of university students and the mean age was 22 years in 1977 and 23 years in the following two years. All the patients were examined for syphilis and all women for gonorrhoea and trichomoniasis. Investigations for Chlamydia trachomatis, Mycoplasma hominis, Ureaplasma urealyticum, Candida albicans, and Herpesvirus hominis infections were carried out according to the presenting symptoms. Non-specific genital infections occurred most commonly $\overparen{\Phi}$ $(25 \cdot 7 \%)$; chlamydia were isolated from $30 \%$ of the patients with non-gonococcal urethritis $\vec{\omega}$ (NGU). The second commonest infection was candidosis (13.5\%). Gonorrhoea, which was found $\stackrel{\infty}{.}$ in $10.6 \%$ of the patients, was diagnosed more frequently in men $(13 \cdot 5 \%)$ than in women $(6 \%)$. No strains of $\beta$-lactamase-producing Neisseria gonorrhoeae were detected and all were sensitive to penicillin. Syphilis was diagnosed in $4.4 \%$ of patients ( $2 \%$ women and $5 \%$ men). Condylomata acuminata were diagnosed in $2.8 \%$ of patients and more frequently in men (4\%). Herpes genitalis and venereophobia were uncommon $(1 \cdot 9 \%$ and $1 \cdot 2 \%$ respectively) and were diagnosed only in men.

\section{Introduction}

Because of the high prevalence of sexually transmitted diseases (STDs) in the world over the last 20 years, and the lack of reliable statistics in Spain, the departments of microbiology and of dermatology and venereology of the University of Seville School of Medicine decided to establish a centre for the diagnosis of STD in the city in order to meet the need for treatment and evaluation of the problem. In particular, we studied three aspects: clinical and microbiological diagnosis and psychosocial factors in the patients attending the centre. The centre was established in February 1977 with a team of gynaecologists, dermatologists, microbiologists, urologists, and psychologists.

\footnotetext{
*Paper read at the 30th General Assembly of the International Union against the Venereal Diseases and Treponematoses, East Berlin, June 1980

Address for reprints: Professor E J Perea, Department of Microbiology and Preventive Medicine, Faculty of Medicine, University of Seville, Seville-9, Spain

Accepted for publication 28 October 1980
}

Throughout the time the centre has been open it $\bar{P}$ has functioned completely independently of any? official Spanish body on account of the lack of on interest on the part of the health authorities in this area.

\section{Patients and methods}

The centre is located at the School of Medicine in the department of microbiology. It consists of three consulting rooms (one for men, one for women, and $N$ another for the use of the psychologist), a waiting room for the patients, and a microbiology laboratory for processing specimens.

Between February 1977 and December 1979, 879 유 patients have attended the centre (534 men and 3450 women); most were university students.

PSYCHOSOCIAL EVALUATION

On arrival patients were first seen for a few minutes by a psychologist, who questioned them briefly about their reasons for attending the centre. This pre- $\stackrel{\mathbb{D}}{\circ}$ liminary interview was found to be beneficial, as 
many patients arrived for the first time in a very anxious state. The patients were then given a questionnaire to complete. This covered 95 psychosocial aspects of STD: identification, religious factors, family environment, social life, education, income, drugs and alcohol, sexual relationships, hygiene, knowledge of STDs, and contact tracing.

As a control group for the study we selected $\mathbf{3 0 0}$ healthy students of similar background who had not attended the centre; these controls also completed the same questionnaire.

\section{CLINICAL INVESTIGATIONS}

The patients were next seen by a physician. During the first two years of the study we used a clinical questionnaire compiled by us, which covered 32 clinical aspects of STD, such as signs, symptoms, and personal history. We are at present co-operating in a multicentre study under the co-ordination of $\mathrm{Dr} \mathrm{J}$ Wallin (Uppsala, Sweden), using the same clinical questionnaire as the other 10 clinics in the study. ${ }^{1}$

\section{MICROBIOLOGICAL INVESTIGATIONS \\ Syphilis}

The Venereal Disease Research Laboratory (VDRL) test $^{2}$ was carried out as a screening procedure on all patients; the fluorescent treponemal antibodyabsorption (FTA-ABS) test ${ }^{3}$ was used to verify the results.

\section{Gonorrhoea}

Gram-stained smears of urethral discharge in men and of cervical secretion in women were examined for the presence of leucocytes and Gram-negative intracellular diplococci. Specimens for culture were collected with calcium-alginate swabs, spread immediately on recently made Thayer-Martin plates, ${ }^{4}$ and kept warm at $37^{\circ} \mathrm{C} .{ }^{5}$ These were incubated in a candle jar at $37^{\circ} \mathrm{C}$, and standard techniques (oxidase and sugar fermentations) were used for identification. All the strains of $N$ gonorrhoeae isolated were tested for sensitivity to antibiotics and for $\beta$-lactamase production by the chromogenic cephalosporin method. ${ }^{6}$

\section{Trichomoniasis}

All women were examined for the presence of Trichomonas vaginalis, yeasts, and number of leucocytes in the genital discharge using wet preparations with the addition of a drop of cresyl blue. Material from male and female patients whose wet preparations gave negative results was tested for $T$ vaginalis by an acridine orange stain. ${ }^{7}$

\section{Chlamydia trachomatis}

Samples were collected from the urethra or from the cervix with calcium-alginate swabs and inoculated into 2SP broth for transport to the laboratory. For culture cycloheximide-treated HeLa 229 cells were used; after 48 and 72 hours' incubation at $35^{\circ} \mathrm{C}$ these were examined after staining with Giemsa stain. ${ }^{8}$

\section{Genital mycoplasmas}

Samples were collected as above and were transported in A3 broth. In the laboratory U9 broth and arginine broth were used for the preliminary isolation of Ureaplasma urealyticum and Mycoplasma hominis respectively. $M$ hominis colonies on A3 agar and PPLO agar were viewed with a microscope. For the detection of $U$ urealyticum colonies, urea- $\mathrm{MnCl}_{2}$ was flooded over the agar plates. ${ }^{9}$

\section{Results}

PSYCHOSOCIAL EVALUATION

Using a $\chi^{2}$ analysis of the results we found significant differences between the patients and the control group. Predominating factors in the patient group were associated with the family-namely a lack of freedom, a dominating father, and a negative relationship between the parents. No significant differences were observed between the sexes, except for those inherent in upbringing such as the greater restrictions on women. ${ }^{10}$

CLINICAL AND MICROBIOLOGICAL DIAGNOSIS The median age of the 879 patients seen in the centre over the three-year period was 23 years; most of the patients were younger but the presence of a few much older patients displaced the median upwards.

The numbers of patients and categories of STD diagnosed on the criteria of signs and symptoms with laboratory confirmation are given in table I. Genital

TABLE I Incidence of STDs in patients attending the clinic between 1977 and 1979

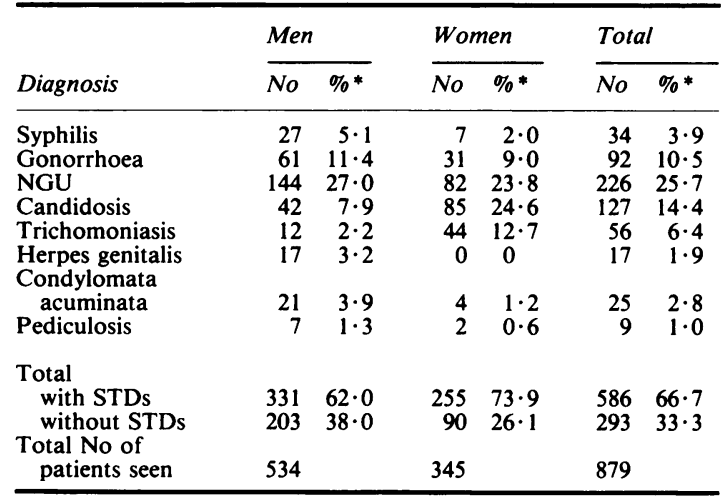

$* \%$ of total No of patients 
candidosis was not considered as an STD. No cases of lymphogranuloma venereum, chancroid, or granuloma inguinale were seen during the study period.

The proportion of men and women who were diagnosed as having an STD rose from $43 \%$ and $29 \%$ in 1977 to $61 \%$ and $56 \%$ respectively in 1979 .

Among the patients who had no STDs the following diagnoses were made: venereophobia $(1 \cdot 2 \%)$, scabies $(1 \%)$, tinea cruris $(0 \cdot 8 \%)$, and folliculosis, seborrhoeic eczema, tinea corporis, and drug allergy $(<0 \cdot 5 \%)$.

\section{Syphilis}

Thirty-four patients ( 27 men and seven women) had syphilis; of these 20 had primary and 14 secondary syphilis. No cases of tertiary or late syphilis were seen.

\section{Gonorrhoea}

Uncomplicated genital gonorrhoea was diagnosed in 92 patients (61 men and 31 women). Two patients had extragenital infections: one had pharyngeal gonorrhoea and another, a male homosexual, a rectal infection. No strains of $N$ gonorrhoeae producing $\beta$-lactamase were detected, and all were sensitive to penicillin.

\section{Nongonococcal urethritis (NGU)}

Using the diagnostic criteria of Alani et al ${ }^{8}$ NGU was diagnosed in 226 patients (144 men and 82 women). $C$ trachomatis was isolated in $30 \%$ of patients with NGU, $U$ urealyticum in $65 \%$, and both $C$ trachomatis and $U$ urealyticum in $15 \%$. In $20 \%$ of the patients no known pathogen was isolated.

\section{INCIDENCE OF STDS}

The incidence of STDs in the three years of the study is shown in table II; syphilis has declined slightly from $5.5 \%$ in 1977 to $3.6 \%$ in 1979 . The incidences of the other STDs have increased; NGU was the most common and pediculosis the most uncommon STD.

TABLE II Changes in incidence of STDs (1977-79)

\begin{tabular}{lrrr}
\hline \multicolumn{3}{c}{ Incidence (\%) } \\
\cline { 2 - 4 } STD & 1977 & 1978 & 1979 \\
\hline Syphilis & 5.5 & 3.5 & 3.6 \\
Gonorrhoea & 12.5 & 8.0 & 13.5 \\
NGU & 12.0 & 30.0 & 28.0 \\
Candidosis & 23.0 & 11.0 & 12.0 \\
Trichomoniasis & 3.5 & 7.0 & 7.0 \\
Herpes genitalis & 1.1 & 2.0 & 2.5 \\
Condylomata & & & \\
acuminata & 2.0 & 2.0 & 4.5 \\
Pediculosis & 1.0 & 1.5 & 2.0 \\
\hline
\end{tabular}

\section{Discussion}

In 1976 and 1977 far-reaching and important political on changes occurred in Spain, which foreshadowed an evolution in the behaviour patterns of our society, including greater sexual liberty. As a result of this, an increase in the incidence of STDs was expected. We decided, therefore, that to investigate this problem in Seville we needed to establish a centre for the $\mathbb{\varnothing}$ diagnosis and treatment of STD. In an attempt to is achieve a more relaxed relationship between patients $\vec{\circ}$ attending the clinic and the medical staff, we deliberately selected young medical officers for their $\vec{\omega}$ lack of prejudice about venereal or sexual matters $\frac{\sigma}{\circ}$ and for their ability to establish a free exchange of information. In this way we hoped to obtain more $y$ complete data from the patients and also to impart to $\omega$ them some basic concepts of hygiene in relation to $\overrightarrow{\vec{V}}$ STDs. From the beginning we decided to see only a few patients a week in the clinic in order to give them more attention and to study the problems in greater depth.

Although, on the one hand, the lack of assistance (financial or otherwise) from official sources of the $\vec{\otimes}$ Spanish Department of Health was a disadvantage in $\stackrel{\infty}{.}$ limiting the scope of our activities because of $\square$ economic factors, on the other hand it allowed us complete freedom to establish a clinic for STD without any external restrictions.

Seville now has 700000 inhabitants, 20000 of whom are students of the University of Seville. When we founded the centre it was publicised among the students; thus, in the first year all the patients were students. In 1978 television and the press made the clinic well known in Spain and the median age of the patients increased.

Two salient individual factors resulting from our psychosocial studies were the lack of religious belief and economic independence, both of which encouraged greater sexual freedom in the patients than in the control group. It appearcd that social and 음 family factors influencing patients with STDs had led, from an early age, to greater emotional instability in their search for total freedom. They had N sexual relationships at an earlier age (16.5 years for women and 16 years for men) than the control group (18 years for both sexes).

Unfortunately, there are still no reliable statistics on STDs in Spain as a whole, and our results may not $\bullet$ give a true picture nationally or in Seville itself. They are, however probably representative of the true $?$ incidence of STD in a university population.

As in many parts of the world ${ }^{13}{ }_{14} \mathrm{NGU}$ was found to be the most common STD $(27 \%$ in men and $24 \%$ in women). These figures show that the incidence of $\stackrel{\unrhd}{\perp}$ NGU is similar to that in other countries. The 
proportions of the various pathogens isolated from patients with NGU in our centre is in general agreement with results published elsewhere. ${ }^{915}$ The second commonest condition was gonorrhoea (13.5\% in men and $6 \%$ in women). These figures were lower than those reported from Sweden, 16 Britain, ${ }^{17}$ Nigeria, ${ }^{18}$ East Africa, ${ }^{19}$ and the USA. ${ }^{20}$ Syphilis is, however, very common in Spain, if our results (5\% for men and $2 \%$ for women) are compared with the previously cited reports. Perhaps this is due to fewer official health surveillance programmes for syphilis in Spain in recent years. Our figures for the incidence of trichomoniasis were higher, and those for herpes genitalis, condylomata acuminata, and pediculosis lower, than those in the reports cited above.

Reviewing the first three years' work of our STD centre (the first and only in Spain) we have reason to be pleased with the functioning of the clinic and the success we have achieved in reaching the public. Nevertheless, it is evident that help from official sources would enable us to broaden our approach and provide a more extensive diagnostic service. In Spain, society needs more support from the Department of Health to achieve an effective control of STDs, especially of syphilis, which appears to be an important health problem in our country.

\section{References}

1. Wallin J. Diagnostics, treatment and epidemiology of STD: an international multicenter study in progress. Abstracts: Sexually Transmitted Disease. 2nd meeting, Helsinki, Finland. August 9-10, 1979.

2. US Department of Health, Education and Welfare. Serologic Tests for Syphilis. Washington: US Government Printing Office, 1964.
3. Hunter EF, Deacon WE, Meyer PL. An improved FTA test for syphilis, the absorption procedure (FTA-ABS). Public Health Rep 1964,79:410-2.

4. Thayer JD, Martin JE. Improved medium selective for cultivation of $N$ gonorrhoeae and $N$ meningitidis. Public Health Rep 1966;81:559.

5. Barlow D, Philips L. Gonorrhoea in women: diagnostic, clinical, and laboratory aspects. Lancet 1978;i:761.

6. O'Callaghan $\mathrm{CH}$, Morris A, Kirby S, Shingler H. Novel method for detection of $\beta$-lactamase by using a chromogenic cephalosporin substrate. Antimicrob Agents Chemother $1972 ; 4: 283-8$

7. Mason PR, Super H, Fripp PU. Comparison of four techniques for the routine diagnosis of Trichomonas vaginalis infection. J Clin Path 1976; 29: 154-7.

8. Alani MD, Darougar S, MacD Burns DC, Thin RN, Dunn H. Isolation of Chlamydia trachomatis from the male urethra. $\mathrm{Br}$ $J$ Vener Dis 1977; 53: 88-92.

9. Taylor-Robinson D, McCormack WM. The genital mycoplasmas (first of two parts). $N$ Engl J Med 1980;302: 1003-10.

10. González-Gabaldón B, Gallardo R, Amakrane Y, Moreno J, Perea EJ. Psycho-social factors in a group of STD patients in Spain. Abstracts: Sexually Transmitted Disease. 2nd meeting, Helsinki, Finland. August 9-10, 1979.

11. Sanders BB jun, Stretcher GS. Warts-diagnosis and treatment. JAMA 1976;235:2859.

12. Ackerman AB. Crabs: the resurgence of Phthirus pubis. $N$ Engl J Med 1968;278:958.

13. Willcox RR. Importance of the so-called "other" STD. Br J Vener Dis 1975;51:221-6.

14. Oriel JD, Schacter J. NGU the Most Common Venereal Disease. San Francisco: GW Hooper Foundation, University of California, 1977

15. Swartz SL, Kraus SJ, Herrman KL, Stargel MD, Brown WJ, Allen SD. Diagnosis and etiology of nongonococcal urethritis. $J$ Infect Dis 1978; 138: 445-54.

16. Wallin J. STD: the present situation in Sweden. Br J Vener Dis 1978;54:24-7.

17. Pemberton J, McCann JS, Mahony JDM, McKenzie C Dougan H, Hay I. Socio-medical characteristic of patients attending a VD clinic and the circumstances of infection. $B r J$ Vener Dis 1972; 38:391-6.

18. Sogbetun AO, Alausa KO, Osoba AO. Sexually transmitted disease in Ibadan, Nigeria. Br J Vener Dis 1977; 53:155-60.

19. Kibukamusoke SW. Venereal disease in East Africa. Trans $R$ Soc Trop Med Hyg 1965;59:642.

20. Fiumara NJ. The Sexually Transmissible Diseases. Disease-amonth. Vol 15, No 3. Chicago: Year Book Medical Publisher Inc, 1978. 